\title{
Exploring preservice student-teachers commitment to community engagement in the second year of training
}

\author{
Salomé Human-Vogel ${ }^{*} a$ and Hanlie Dippenaar ${ }^{b}$ \\ ${ }^{a}$ Department of Educational Psychology, University of Pretoria, South Africa; ${ }^{b}$ Department of Humanities \\ Education, University of Pretoria, South Africa.
}

\begin{abstract}
In this study we report on a preliminary study to examine the utility of the Community Engagement Commitment Scale to examine the factors that predict student-teachers' commitment to community engagement in the second year of study at a South African university. Independent variables included Dalbert's (1998) personal belief in a just world, an adaptation of Rusbult et al's (1998) original predictors of Level of Commitment (Satisfaction, Quality of Alternatives, Investment size), and a new factor, Meaningfulness. The latter factor is based theoretically on the work of Lieberman (1998) and Heine, Proulx and Vohs (2006) and was included to study the extent to which identity-expression could be related to Level of Commitment. We administered the Community Engagement Commitment Scale on a nonrandom sample of 414 student-teachers in their second year of study who all participated in compulsory community engagement project. The results support a four factor model of Commitment with Meaningfulness, Quality of Alternatives and Investment as predictors of Level of Commitment. Surprisingly, all the Satisfaction items loaded with the Level of Commitment items on one factor. Together, Meaningfulness, Quality of Alternatives and
\end{abstract}

\footnotetext{
* Corresponding author. Email: salome.humanvogel@up.ac.za
} 
Investment accounted for approximately two-thirds of the variance in Level of Commitment. Significant $(\mathrm{p}<.01)$ language group differences were also observed on Meaningfulness and Level of Commitment. The results of the study suggest the importance of studying meaningfulness as an additional predictor of level of commitment in community engagement contexts.

Keywords: pride, commitment, satisfaction, quality of alternatives, investment size, personal belief in a just world, pre-service teachers, community engagement

\section{Introduction}

Given that the transition from school to university is widely acknowledged as a tumultuous time in which students have to focus on future goals while learning to negotiate the stresses of academic life (Morosanu, Handley \& O'Donovan, 2010), it is not surprising that much research in the context of higher education centers on the "student experience" (Matthews, Andrews \& Adams, 2011) and the likelihood that students will complete their higher degree. As Willcoxson (2011) points out, much of the research on student attrition focuses on students in their first year when factors such as personality, social and academic integration, age and grade point average are likely predictors of drop-out. In the second year of study, factors more strongly associated with students' decision to quit their studies include loneliness, lack of purpose in studies, lack of social integration and feelings of academic inadequacy, although there do seem to be discipline-specific differences with students in Education and Arts more likely to drop-out in the second year and Science students dropping out in the first year (Willcoxson, 2011). One way that Universities typically respond to student drop-out is to create support structures intended to foster a sense of community, and to help 
students feel a sense of belonging. Efforts such as these are generally intended to facilitate positive student life experiences. Matthews et al. (2010) have suggested that social networks can help to create a sense of belonging that may lead to greater academic engagement, but as Morosanu et al. (2010) point out, imposed (top-down) social support strategies or communites of learning are generally less effective.

Efforts to prevent attrition, retention and engagement at university are often focused on the promotion of student satisfaction (Matthews et al., 2010; Morosanu et al. 2010; Stupans, Scutter, \& Pearce, 2010). Broadly speaking, students' satisfaction can be enhanced by providing a positive study environment, quality education and good teaching, and by providing opportunity for social networking. Denson, Loveday and Dalton (2010) have demonstrated that overall satisfaction can be predicted broadly by student demographic variables (gender and local/international status of student) and the reason for enrolling for a particular course (e.g. whether required or part of the student's career plans). Interventions that focus on increasing satisfaction, such as introducing "fun" and engaging learning activities in the form of a play to teach chemistry equations, can lead to improvement in student learning and subsequently also students' course evaluations (Stupans et al., 2010). Students also report greater satisfaction upon the introduction of facilities where they can socialise with friends while studying (Matthews et al., 2010). Other research have pointed to the importance of enhancing student engagement as a way of improving retention (Horstmanshof \& Zimitat, 2007).

One of the broad goals of higher education is to prepare students to participate in civic life (Iverson \& James, 2010). Civic participation requires a personally felt sense of responsibility, participation, and an appreciation of social justice, as described by Westheimer and Kahne's (2004) notion of three types of citizens, i.e. the personally responsible, 
participatory and justice-oriented citizen. Westheimer \& Kahne (2004) point out that academic service-learning is one approach that universities utilize to strengthen democracy through education and it reflects universities' commitment to its local community (Boland, 2009). Academic service learning typically entails connecting a community engagement project to a credit-bearing module with the purpose of providing students with authentic opportunities to apply classroom learning outside the classroom, while rendering a service to the community (see Smith et al. 2011). At the South African University where this study was conducted, community engagement is a compulsory component of undergraduate teacher training where all teaching students are required to learn how to develop language skills in a country where most learners do not learn in their mother tongue. Most of the community projects in the present study take place in areas that are under-resourced and disadvantaged in terms of service delivery (as in previously black townships), or where access to resources are limited (as in prisons). All sites offered opportunities for authentic learning with vulnerable children, most of whom are affected by HIV/AIDS and poverty, afterschool programmes or orphanages, or juvenile learners in prisons. Having been confronted with vulnerable learners in disadvantaged contexts, we believe that students' personal beliefs about justice would be related to their commitment to their community engagement project. A personal belief in a just world indicates the belief that one is usually treated fairly and justly and is indicative of the social contract to also behave fairly and justly toward others (Dalbert, 1999). Consequently, we hypothesize that students with a strong personal justice framework will be more likely to realise the importance of community service, experience it as more meaningful and satisfying, and will therefore be more committed to community engagement.

Community engagement projects can be approached in various ways. Iverson and James (2010) describe a range of philosophies that embrace change-oriented service learning with the 
goal of addressing the root causes of societal ills on one end, and charity-oriented activities that have been criticised for tending to the symptoms only and described somewhat derisively as volunteerism on the other end. Regardless, the rationale for the inclusion of academic servicelearning projects into the curriculum is generally presented as fostering academic engagement on a deeper level by emphasising integrated learning, community service, collaboration, civic engagement, contemplation and evaluation (Power, 2009; Smith et al., 2011). Engagement in an academic context generally refers to students' active involvement in their learning, the quality of their effort and the extent to which they make effective use of the environment to promote learning (Krause \& Coates, 2008). In the context of the present study, academic engagement is regarded as a consequence of commitment. If students are committed to their studies, their behaviours should reflect such commitment and serve to maintain the commitment. We argue that students who are committed to a particular course of action will regulate their behaviour to maintain that course of action. Broadly speaking, service learning aims to encourage citizenship, which requires personal and social responsibility (Westheimer \& Kahne, 2004) through meaningful engagement which, as Iverson and James (2010) point out, seem to be particularly relevant for student-teachers. The underlying assumption to this approach is that students who participate in academic service learning projects that provide opportunities for learning in authentic contexts will have a deeper, more meaningful learning experience and will consequently be less likely to discontinue their studies. There is some evidence that this can be the case. Moely, McFarland, Miron, Mercer \& Ilustre (2002) reported in their study that participation in academic service learning was related increased awareness of social justice issues, as well as future plans to continue involvement in civic activities. Madsen and Turnbull (2006) say that their participants reported personal benefits such as feeling valued, experiencing satisfaction from helping others, being more motivated and describing a sense of fulfillment. Krypel and Henderson-King (2010) investigated the relationship between 
students' meanings of education and stress, coping and optimism and found that a disengagement coping style was associated with more negative meanings of education, implying that students who are encouraged to engage in meaningful educational opportunities in their undergraduate years may be less likely to disengage from academic studies. Based on these findings, we hypothesized that the meaningfulness of community engagement would predict overall commitment for pre-service student-teachers.

\section{Meaningfulness and community engagement commitment}

In the present study we examined pre-service student-teachers' commitment to community engagement with Rusbult, Maritz and Agnew's (1998) investment model of commitment. Rusbult et al. (1998) describe satisfaction, quality of alternatives (availability of better alternatives) and investment size (time and effort put in) as the strongest predictors of level of commitment. Studies of interpersonal commitment (romantic commitment in particular) provide the strongest evidence for the model, and promising results have also been reported for non-romantic domains of commitment such as work and sport (Le \& Agnew, 2003). Meta-analyses of the findings in various domains using the model confirm the robustness of Satisfaction, Quality of Alternatives and Investment as predictors of commitment, accounting for about two-thirds of the variance in level of commitment (Le \& Agnew, 2003). Although the predictive power of the model is diminished in non-interpersonal contexts (Le \& Agnew, 2003), further testing was recommended with a view to expanding the utility of the model in non-interpersonal domains (Le \& Agnew, 2003). The model was consequently adapted to reflect community engagement as the object of commitment. In addition, based on Lieberman's (1998) analysis of identity processes in commitment, and the acknowledgement that meaning is a basic human need required for personal wellbeing (Heine, 
Proulx and Vohs, 2006; Steger \& Kashdan, 2007), we wanted to investigate meaningfulness as an additional possible explanatory factor to level of commitment.

Thus, meaningfulness in the present study was operationalized as a specific indicator of the extent to which the object of commitment is experienced as meaningful. This conceptualisation of meaningfulness is different from the description of meaning as described in measures such as the Meaning in Life Questionnaire (Steger \& Kashdan, 2006) or Antonovsky's measurement of meaning in the Sense of Coherence Scale (Antonovsky \& Sagy, 2001) because we did not want to measure a general sense of purpose or meaning in life. We specifically defined meaningfulness as depending on the extent to which individuals feel they can express their identity through community engagement and that their involvement in their community engagement project supports expression of their sense of self. Accordingly, we argue that the meaningfulness of community engagement involvement would be positively related to a strong personal belief in a just world because participants with a strong personal justice motive should find community engagement in disadvantaged settings meaningful.

We hypothesized that, in line with previous research (Le \& Agnew, 2003) that Satisfaction and Investment would be positively related to Level of commitment, Alternatives would be inversely related to Level of commitment, and that Meaningfulness would be positively related to Level of commitment as well as provide additional predictive power beyond Satisfaction, Alternatives and Investment. Additionally, we hypothesized that participants' personal belief in a just world would be positively related to all the study variables, except for Alternatives where we expected an inverse relationship. 


\section{Method}

\section{Instruments}

Personal belief in a Just World Scale. Participants' beliefs about personal justice was measured using Dalbert's (1999) Personal Belief in a Just World Scale. The scale consists of seven items (Sample item: Overall, events in my life are just, $\alpha=.75$ ) with a six-point Likerttype scale.

Community Engagement Commitment Scale. This scale was developed for the present study and is based on the Rusbult, Maritz \& Agnew (1998) investment model of commitment. The scale consists of three subscales each using five items to measure Satisfaction, Quality of Alternatives, and Investment size as predictors of the dependent variable, Commitment level. For the present study, the instrument was adapted to reflect commitment in a non-interpersonal domain by preserving the general wording of the items on the original subscales, but changing the object of commitment to reflect community engagement. Examples of the adaptation of the items for each subscale is presented in Figure 1.

\begin{tabular}{ll}
\hline \multicolumn{1}{c}{ Original Commmitment Scale (Rusbult et al., 1999) } & Adapted Community Engagement Commitment Scale \\
\hline Satisfaction & Satisfaction \\
My relationship is close to ideal & Being able to work in the community is close to ideal. \\
\hline Quality of Alternatives & Quality of Alternatives \\
My alternatives are attractive to me (dating another, & My alternatives to community work are attractive to me \\
spending time with friends or on my own, etc.) & (spending time on my own, social activities) \\
\hline Investment & Investment \\
Compared to other people I know, I have invested a great & Compared to others I know, I have put a lot into working in \\
deal in my relationship with my partner. & the community. \\
\hline Level of Commitment & Level of Commitment \\
I am committed to maintaining my relationship with my & I want to be involved in community work long after I finish \\
partner. & my training. \\
\end{tabular}

Figure 1: Adaptation of items from the Rusbult et al. (1998) model of commitment for the Community Engagement Commitment Scale 
An additional subscale was created to measure Meaningfulness as a predictor of Commitment Level. Meaningfulness was operationalized from a motivational perspective as the extent to which students report their (i) community work to be important to them as well as (ii) identity-relevant, and (iii) whether their involvement in community work facilitates selfexpression. Sample items for the Meaningfulness subscale include Community work means a lot to me (Importance); Community work contributes to shaping who I am (Identity-relevance); and Community work gives me the opportunity to express an important part of who I am (Selfexpression). The piloted instrument contained a total of 30 items, which were subjected to exploratory factor analysis.

\section{Participants}

A non-random sample of 414 student-teachers in their second year of study at a South African University participated in the investigation. The study received ethical clearance from the institution where it was conducted. Students were requested to complete the two instruments, which was combined into a single questionnaire, anonymously and to leave it in a box in the second author's office. All participants had completed 20 hours of community service as part of the module requirements for their course in settings which had established relationships with the university, or they could find their own community site and apply for permission to do their projects at the site. Permission was granted based on specific requirements such as the availability of mentors to monitor students' work at the site. Participants' ages varied between 19 - 35 years $(M=20.6 ; S D=1.70)$. Approximately $96 \%$ of the participants ranged between 19 - 23 years. The sample consisted of 73 male students $(18 \%)$ and 341 female students (82\%). Descriptive statistics are presented in Table 1. 
Table 1 : Descriptive statistics of the sample $(n=414)$

\begin{tabular}{|c|c|c|}
\hline & $f$ & $\%$ \\
\hline \multicolumn{3}{|l|}{ Gender } \\
\hline Male & 73 & 18 \\
\hline Female & 341 & 82 \\
\hline \multicolumn{3}{|c|}{ Age in years ( $N=414 ; M=20.5$ years; $S D=1.7$ years) } \\
\hline \multicolumn{3}{|c|}{ Home language $(N=414)$} \\
\hline Afrikaans & 228 & 55.1 \\
\hline English & 83 & 20 \\
\hline African language $^{1}$ & 103 & 24.9 \\
\hline \multicolumn{3}{|c|}{ Is community work important? $(N=411)$} \\
\hline Yes & 400 & 96.6 \\
\hline No & 11 & 2.7 \\
\hline Missing values & 3 & .7 \\
\hline \multicolumn{3}{|c|}{ Did your community work include working with people from a different cultural background? $(N=409)$} \\
\hline Yes & 374 & 90.3 \\
\hline No & 35 & 8.5 \\
\hline Missing value & 5 & 1.2 \\
\hline
\end{tabular}

\section{Results}

\section{Community Engagement Commitment Scale}

An item-analysis was conducted on the 22 items of the adapted Community Engagement Commitment Scale together with the eight additional items that were written to measure Meaningfulness. The results are presented in Table 2.

The internal consistency of the scale was acceptable $(\alpha=.94)$. Four items (CI1; CA2,CA3 and CA5 had item-total correlations less than $r=.30$, so they were discarded, increasing the scale Alpha to .90. The structure of the scale (26 items) was examined next using principal components analysis. Five factors were identified with Eigenvalues $>1$, but inspection of the items revealed that the two items that loaded on Factor 5, are both negatively worded items that were answered in a positive direction. Seeing that these are only two of seven items originally 
Table 2 : Item analysis of the adapted community engagement commitment scale $(N=412 ; \alpha=.94)$

\begin{tabular}{|c|c|c|c|c|}
\hline $\begin{array}{l}\text { Item } \\
\mathrm{Nr}\end{array}$ & Item wording & $M$ & $S D$ & $\begin{array}{l}\text { Item- } \\
\text { total } r\end{array}$ \\
\hline & Level of Commitment & & & \\
\hline CL1 & I am committed to working in disadvantaged communities. & 4.88 & 1.11 & .66 \\
\hline CL2 & I want to be involved in community work long after I finish my training. & 4.87 & 1.20 & .74 \\
\hline CL3 & I feel very attached to the communities I work in - very strongly linked to them. & 4.66 & 1.21 & .70 \\
\hline CL4 & $\begin{array}{l}\text { It is likely that I will stop working in the community as soon as I finish my } \\
\text { training. }\end{array}$ & 4.14 & 1.53 & .35 \\
\hline CL5 & I would not feel very upset if I could no longer be involved in community work. & 4.15 & 1.50 & .50 \\
\hline CL6 & $\begin{array}{l}\text { I want my relationships with people in the community to continue for a long } \\
\text { time. }\end{array}$ & 4.81 & 1.15 & .67 \\
\hline \multirow[t]{2}{*}{ CL7 } & I am oriented towards the long term future of the community where I work. & 4.61 & 1.18 & .68 \\
\hline & Satisfaction & & & \\
\hline CS1 & I feel satisfied with my work in the community. & 5.02 & .86 & .37 \\
\hline CS2 & Doing community work is much better than doing other things. & 4.54 & 1.17 & .67 \\
\hline $\mathrm{CS} 3$ & Being able to work in the community is close to ideal. & 4.52 & 1.10 & .72 \\
\hline CS4 & My community work makes me very happy. & 4.94 & 1.00 & .75 \\
\hline \multirow[t]{2}{*}{ CS5 } & $\begin{array}{l}\text { Community work does a great job of fulfilling my needs for giving something } \\
\text { back. }\end{array}$ & 5.10 & .98 & .73 \\
\hline & Quality of Alternatives & & & \\
\hline CA1 & I would prefer to do other things than community work. & 4.17 & 1.49 & .60 \\
\hline CA2 & $\begin{array}{l}\text { The alternatives to community work are close to ideal (studying, reading; doing } \\
\text { assignments) }\end{array}$ & 3.45 & 1.49 & .28 \\
\hline CA3 & $\begin{array}{l}\text { My alternatives to community work are attractive to me (spending time on my } \\
\text { own, social activities) }\end{array}$ & 3.20 & 1.43 & .26 \\
\hline CA4 & I would rather spend time on assignments or reading. & 4.15 & 1.41 & .54 \\
\hline CA5 & $\begin{array}{l}\text { My needs for giving something back could be fulfilled just as easily with other } \\
\text { things. }\end{array}$ & 3.83 & 1.52 & .31 \\
\hline CI1 & $\begin{array}{l}\text { Investment } \\
\text { I have invested a lot in community work that would count for nothing if I } \\
\text { stopped. }\end{array}$ & 3.72 & 1.48 & .17 \\
\hline $\mathrm{Cl} 2$ & Compared to others I know, I have put a lot into working in the community. & 4.56 & 1.12 & .48 \\
\hline $\mathrm{Cl} 3$ & $\begin{array}{l}\text { I feel very involved with the communities where I work - I have put in a great } \\
\text { deal of time and effort }\end{array}$ & 4.67 & 1.08 & .61 \\
\hline CI4 & $\begin{array}{l}\text { Many aspects of my life are linked to the communities in which I work and I } \\
\text { would lose this if I did not work there anymore. }\end{array}$ & 3.85 & 1.35 & .43 \\
\hline CI5 & I could use my time better if I did not have to spend so much of it on & 4.26 & 1.41 & .49 \\
\hline
\end{tabular}


community work.

\begin{tabular}{llrrr}
\hline & Meaningfulness & & \\
\hline CM1 & Community work means a lot to me. & 4.96 & 1.00 & .79 \\
CM2 & Community work plays an important role in my life. & 4.74 & 1.11 & .79 \\
CM3 & Overall, community work adds meaning to my life. & 4.87 & 1.05 & .79 \\
CM4 & Working in the community is meaningful to me. & 4.99 & .96 & .78 \\
CM5 & Community work gives me the opportunity to express an important part of who & 4.86 & 1.11 & .77 \\
& I am. & 4.89 & 1.09 & .70 \\
CM6 & Community work contributes to shaping who I am. & 4.69 & 1.47 & .59 \\
CM7 & I'm not the kind of person to do community work. & 4.63 & 1.23 & .63 \\
CM8 & Community work allows me to be who I want to be. & & \\
\hline
\end{tabular}

adapted for the Commitment Level subscale, it was thus decided not to include them in further analyses. The full scale was subjected to a factor analysis again, and a four-factor solution seemed to provide the best explanation for the data. See Table 3.

The items loading on Factor 1 were the items written to measure meaningfulness and this Factor is accordingly called the Meaningfulness scale. Interestingly, the items reflecting Level of Commitment and Satisfaction subscales combined to load only on one Factor, accordingly called Level of Commitment. The third factor consists of two Quality of Alternative items, and two items (CM7; CI5) that were written for the Meaningfulness and Investment Scale. Considering the meaning of the items, they seem to reflect a consideration of quality of alternatives and therefore we combined them to form the Quality of Alternatives subscale. The last factor consisted of three Investment items and are thus called the Investment scale. All four scales had good internal consistency (Level of Commitment $\alpha=.92$; Meaningfulness $\alpha=$ .95; Alternatives $\alpha=.76$; Investment $\alpha=.75$ ). The items reflected in the principal components analysis in Table 3 were used to compute the average scale score which was used in further analyses. A correlational analysis using the bootstrap method (1000 samples, $95 \%$ confidence 
Table 3 : Factor loadings of the 26 items of the Community Engagement Commitment scale $(N=412 ; \times \mathbf{X}=.95)$

\begin{tabular}{|c|c|c|c|c|}
\hline Factor 1 (7 items; $\alpha=.95)$ & F1 & F2 & F3 & F4 \\
\hline Community work gives me the opportunity to express an important part of who I am. (CM5) & .88 & .03 & .01 & .00 \\
\hline Overall, community work adds meaning to my life. (CM3) & .85 & .00 & .04 & .08 \\
\hline Community work contributes to shaping who I am. (CM6) & .82 & .13 & -.07 & -.07 \\
\hline Community work plays an important role in my life. (CM2) & .81 & .02 & .02 & .16 \\
\hline Community work allows me to be who I want to be. (CM8) & .81 & .07 & -.11 & -.02 \\
\hline Community work means a lot to me. (CM1) & .72 & .03 & .13 & .12 \\
\hline \multicolumn{5}{|l|}{ Factor $2(10$ items; $\alpha=.92)$} \\
\hline I want to be involved in community work long after I finish my training. (CL2) & .20 & .79 & .03 & -.22 \\
\hline I am committed to working in disadvantaged communities. (CL1) & -.05 & .78 & .09 & -.04 \\
\hline I feel very attached to the communities I work in - very strongly linked to them. (CL3) & .13 & .75 & -.06 & .02 \\
\hline I feel satisfied with my work in the community. (CS1) & -.54 & .72 & -.03 & .47 \\
\hline Community work does a great job of fulfilling my needs for giving something back. (CS5) & .14 & .57 & .20 & -.03 \\
\hline I want my relationships with people in the community to continue for a long time. (CL6) & .33 & .54 & -.04 & -.02 \\
\hline \multicolumn{5}{|l|}{ Factor 3 ( 4 items; $\alpha=.76$ ) } \\
\hline I could use my time better if I did not have to spend so much of it on community work. (CI5) & .06 & .12 & -.90 & -.05 \\
\hline I would rather spend time on assignments or reading. (CA4) & .14 & -.13 & -.77 & .00 \\
\hline I would prefer to do other things than community work. (CA1) & -.08 & -.11 & -.63 & .05 \\
\hline I'm not the kind of person to do community work. (CM7) & -.23 & .04 & -.62 & .04 \\
\hline
\end{tabular}


Factor 4 ( 3 items ; $\alpha=.75)$

Compared to others I know, I have put a lot into working in the community. (CI2)

I feel very involved with the communities where I work - I have put in a great deal of time and effort (CI3)

Many aspects of my life are linked to the communities in which I work and I would lose this if I did not work there anymore. (CI4)

$\begin{array}{llll}.06 & -.05 & .01 & \mathbf{. 8 5} \\ .13 & -.05 & .18 & \mathbf{. 7 6} \\ .36 & -.05 & -.21 & \mathbf{. 6 1}\end{array}$

Notes. Principal components analysis with promax rotation. Rotation converges in 6 iterations. Communalities were all >.500; KMO $=.949 ; \mathrm{Bartlett's} \mathrm{test} \mathrm{of} \mathrm{sphericity}=\chi^{2}=7104.11, \mathrm{p} .000$ 
level) was conducted to inspect the hypothesised relationships between the study variables (see Table 4). The significance level was set at $p<.05$.

Table 4: Zero-order correlations $(\mathrm{N}=379)$

\begin{tabular}{|c|c|c|c|c|c|c|c|}
\hline & & & 1 & 2 & 3 & 4 & 5 \\
\hline \multirow[t]{5}{*}{1} & BJW & & 1 & & & & \\
\hline & Std.Error & & & & & & \\
\hline & 95\% Confidence Level & & & & & & \\
\hline & & Lower & & & & & \\
\hline & & Upper & & & & & \\
\hline \multirow[t]{5}{*}{2} & Commitment Level & & .07 & 1 & & & \\
\hline & Std.Error & & .06 & & & & \\
\hline & 95\% Confidence Level & & & & & & \\
\hline & & Lower & -.05 & & & & \\
\hline & & Upper & .17 & & & & \\
\hline \multirow[t]{5}{*}{3} & Meaningfulness & & .04 & $.78^{* *}$ & 1 & & \\
\hline & Std.Error & & .06 & .04 & & & \\
\hline & 95\% Confidence Level & & & & & & \\
\hline & & Lower & -.07 & .70 & & & \\
\hline & & Upper & .15 & .84 & & & \\
\hline \multirow[t]{5}{*}{4} & Quality of Alternatives & & -.00 & $-.63 * *$ & $-.59 * *$ & 1 & \\
\hline & Std.Error & & .06 & .04 & .04 & & \\
\hline & 95\% Confidence Level & & & & & & \\
\hline & & Lower & -.11 & -.70 & -.67 & & \\
\hline & & Upper & .11 & -.55 & -.50 & & \\
\hline \multirow[t]{5}{*}{5} & Investment & & $.11^{*}$ & $.58 * *$ & $.59 * *$ & $-.37 * *$ & 1 \\
\hline & Std.Error & & .05 & .05 & .04 & .05 & \\
\hline & 95\% Confidence Level & & & & & & \\
\hline & & Lower & .00 & .48 & .51 & -.46 & \\
\hline & & Upper & .21 & .66 & .66 & -.27 & \\
\hline
\end{tabular}

Very surprisingly, correlations for Dalbert's (1999) personal belief in a just world scale with the other study variables were close to zero, indicating no relationship between personal justworld beliefs and all variables but Investment $(r=.11 ; \mathrm{p}=.04)$. The pattern of correlations for the community engagement commitment scale were in the expected directions with all 
correlations highly significant $(p<.001)$. Level of Commitment and Meaningfulness were very highly correlated $(r=.78 ; \mathrm{p}=.000)$. A series of interaction analyses indicated that there were no significant interactions between the personal belief in a just world, quality of alternatives, investment and meaningfulness as potential predictors of level of commitment as dependent variable. A series of multiple regression analyses was conducted with standardised variables to reduce the effect of multicollinearity, the first of which examined the role of demographic variables such sex and home language on level of commitment. Only home language contributed significant predictive power $\left(R^{2}=.05, d f=1,406, p=.000\right)$. Next, we tested Rusbult's model of commitment by regressing Level of commitment on Home language (Block 1), Meaningfulness (Block 2), Alternatives (Block 3) and Investment (Block 4). This model was significant $\left(R^{2}=.66, F=193.16, p=.000\right)$ with all predictors except home language contributing significantly to predicting variance in the dependent variable (Meaningfulness $-\Delta R^{2}=.56, \beta=.53, d f=1,395, p=.000$; Alternatives $-\Delta R^{2}=.04, \beta=-.25, d f$ $=1,394, p=.000$; Investment $\left.-\Delta R^{2}=.02, \beta=.18, d f=1,391, p=.000\right)$. We interpreted this finding as positive construct-related evidence for the validity of the adapted commitment model in a community engagement context. Together, Meaningfulness, Quality of Alternatives and Investment accounted for about two-thirds of the variance in Level of Commitment as described in the literature for the original model (Le \& Agnew, 2003).

\section{Group differences}

Interesting group differences emerged between the three main language groups in the sample (Afrikaans, English, African). A one-way analysis of variance (ANOVA) was conducted with the home language group as the independent variable and the study variables as dependent variables. Because of unequal group sizes, Levene's test of homogeneity of variance was used to examine homogeneity of variance for the three groups. The test was insignificant 
for all the study variables. Significant between-group differences emerged for all the commitment variables, but not for personal just-world beliefs (see Table 5).

Table 5: Between-group differences for home language group $(d f=2)$

\begin{tabular}{|c|c|c|c|c|c|c|c|}
\hline & & \multicolumn{2}{|c|}{ Afrikaans } & \multicolumn{2}{|c|}{ English } & \multicolumn{2}{|c|}{ African } \\
\hline & $F$ & $M$ & $S E$ & $M$ & $S E$ & $M$ & $S E$ \\
\hline BJW & 2.22 & 4.23 & .05 & 4.19 & .09 & 4.03 & .09 \\
\hline Meaningfulness** & 16.85 & 4.63 & .06 & 4.99 & .10 & 5.29 & .08 \\
\hline Alternatives* & 3.87 & 2.82 & .08 & 2.53 & .11 & 2.58 & .11 \\
\hline Investment* & 3.37 & 4.27 & .06 & 4.39 & .10 & 4.58 & .09 \\
\hline Commitment level** & 9.05 & 4.65 & .06 & 4.94 & .08 & 5.04 & .08 \\
\hline Notes: ${ }^{*} p<.05 ;{ }^{* *} p<$. & & & & & & & \\
\hline
\end{tabular}

The Scheffé test was utilised as a post-hoc measure to further examine mean differences between groups. On level of commitment, between Afrikaans- and English speaking groups and Afrikaans and African groups. In both cases, Afrikaans-speaking students reported a significantly lower mean level of commitment in comparison to English $(p=.02)$ and African participants $(\mathrm{p}=.001)$. The same pattern was observed for Meaningfulness, where Afrikaansspeaking students reported significantly lower mean scores than English $(\mathrm{p}=.02)$ and African participants $(\mathrm{p}=.000)$. On the Investment scale, the only significant difference was between Afrikaans and African participants, the latter reporting significantly higher mean Investment than Afrikaans participants $(\mathrm{p}=.04)$. Although the analysis of variance indicated significant between-group differences on the Alternatives scale, the post-hoc test failed to indicate any specific differences between individual groups.

An independent samples t-test (bootstrap method of 1000 samples, 95\% confidence level) revealed a significant mean difference of 0.63 for Quality of Alternatives between groups who either worked with culturally different people or not $(t(373)=-3.06, p=.002 ; 95 \%$ CI[-1.05, .20]). Those who worked with people from a different cultural background to themselves 
reported a lower mean on Quality of Alternatives than those who worked with people who were culturally more similar to themselves. This implies that those who worked with culturally different people were less likely to report that they would rather want to do other things than community work. Interestingly, a significant difference $(t=2.41(377) ; \mathrm{p}=.02)$ also emerged between males and females on Quality of Alternatives with males more likely to report that they would rather do something else than community work.

\section{Discussion}

The purpose of the present study was to examine the utility of the Rusbult et al. (1998) model of commitment in a non-relational domain such as community engagement. We hypothesised that (i) students' personal beliefs of justice, satisfaction and investment would be positively related to community engagement commitment, (ii) Quality of Alternatives would be inversely related to Level of Commitment, and (iii) Meaningfulness would predict additional variance in Level of commitment over and above the existing predictors. The utility of the adapted Rusbult et al. (1998) scale for community engagement commitment was supported. A four-factor model was supported by the data, but Satisfaction and Level of commitment items loaded on a single factor. The newly written Meaningfulness items took the place of Satisfaction in predicting the most variance in Level of commitment. The final scales had good internal consistency and the pattern of correlations was in the expected directions. Consistent with findings from other studies (Le \& Agnew, 2003), the Quality of Alternatives and Investment scales in the present study contributed to predicting significant, but less variance in level of commitment. This is not surprising, since the students are expected to complete a certain number of hours in their community engagement project in order to complete and pass their academic module. 
The addition of the Meaningfulness items in the scale seems to have yielded promising results. Firstly, the findings provide evidence of the utility of Meaningfulness as a predictor of community engagement commitment in particular, and perhaps also of commitment in general. Of all the study variables, Meaningfulness was most strongly correlated with Level of Commitment, and in regression analyses it provided more predictive power than Quality of Alternatives and Investment. Because the satisfaction items loaded on a different factor than the meaningfulness items, we believe this provides some support for the fact that Satisfaction and Meaningfulness do not measure exactly the same construct. Steger and Kashdan (2007) have pointed out that life satisfaction and meaning in life can be expected to converge and share significant variance, as also demonstrated by the correlations between Level of commitment (which contained the Satisfaction items) and Meaningfulness. It would be important in future studies to disentangle the effects of the two variables. We argue that meaningfulness, because it relies on stable identity processes, may be less vulnerable to situational change than satisfaction and thus explain some of the stability in sustained commitment. Our results suggest there may be merit in studying identity processes in commitment and more specifically, the hypothesis that commitments should be more stable when they are experienced as personally meaningful, as opposed to satisfactory only. One possible hypothesis would be that personally meaningful commitments can be sustained in the [temporary] absence of satisfaction, but that personally meaningless commitments are highly unlikely to be satisfactory and therefore unlikely to be sustained. Although life satisfaction and meaning in life (as more general constructs) both seem to be relatively stable over time (Steger \& Kashdan, 2007), it has been acknowledged that satisfaction is sensitive to changes due to life events (Lucas \& Donnellan, 2007). Similarly, there may necessarily be times when commitments are not necessarily a source of satisfaction, but are maintained because they are perceived as personally meaningful in the greater scheme of things. With regard to student 
attrition, it may therefore be worthwhile to study the personal, interpersonal and institutional factors that promote personal meaning in addition to satisfaction when understanding commitment. It should be mentioned however, that personal meaning as conceptualised in this study involves a "fit" between the person and the environment, indicating that much of what is important in students' commitments, is linked to their identity, or sense of self. Arguably, also important therefore in regulating the type of commitments students make, are students' identity styles - the extent to which they have explored and committed to an identity - which seem to be related to academic performance. (Berzonsky \& Kuk, 2005). We recommend that future studies investigate the relationship between identity style and predictors of commitment to further understand the role that identity plays in students' ability to form and maintain commitments, and to measure academic engagement (Krause \& Coates, 2008) and academic performance as some of the consequences of commitment.

The absence of any significant correlation between participants' personal justice beliefs and their commitment to community engagement was very unexpected. That students' beliefs about personal justice seem to be independent of their attitudes about community engagement seems counterintuitive. A personal belief in a just-world indicates how strongly an individual believes that the world is just and fair, and also indicates an obligation to behave fairly and justly toward others (Dalbert, 1999). Presumably, when faced with injustice, a person with a strong belief in a just world will attempt to restore justice by either blaming the victim or taking action to restore justice, although it has also been noted that people who believe in a just world do not feel a need to change the world (Dalbert, Lipkus, Sallay \& Goch, 2001). Community engagement initiatives almost always take place in disadvantaged communities, as was the case with our study, and could therefore be argued to rely strongly on the perceived obligation to promote or restore social justice by serving and empowering those who are less 
fortunate. The findings of the present study suggest that students find their involvement in community engagement projects personally meaningful, and they derive satisfaction from it, but their involvement do not seem to be associated with or motivated by any personal beliefs about justice. Moreover, this was true for Afrikaans, English and African speaking participants. It raises the question whether the students in our sample would have chosen to spend time on community engagement activities if it were not compulsory. From this perspective, the findings of the current study may reflect obligation rather than commitment and a "if life hands you a lemon make lemonade" attitude towards community engagement.

Arguably, obligation implies commitment without the perceived freedom of choice, such as was the case for the students in our sample. It does not preclude deriving personal meaning and satisfaction from such engagement, but it is also not particularly associated with strong investments and low quality of alternatives. Interestingly, the African speaking participants were significantly more likely than Afrikaans-speaking participants to report greater meaningfulness and level of commitment. Additionally, the participants who worked with people who were culturally different from them also reported lower levels of Quality of Alternatives with their community engagement activies, providing some initial evidence of the positive effect that culturally diverse settings can have on participants. We believe that a very different pattern of findings may be obtained for a different sample, say community volunteers who work in a community setting out of personal choice. Nevertheless, the findings are suggestive of the fact that students who participate in community engagement projects as part of their academic training may not necessarily be receptive to pedagogies that emphasise personal responsibility and social justice in community engagement. It may be that the overriding factor for students is simply to complete their academic training and to do what it takes to be successful in their studies. On the other hand, it can be argued that social justice 
issues should be integrated more strongly into curricula that have integrated community engagement activities.

A limitation of the current study is that we did not collect data on our participants' academic performance at university, which would have permitted inferences about the impact of participants' commitment to community engagement on their academic grades. Thus, although it appears as if the model that was tested in the present study can measure commitment in a community engagement domain meaningfully, it is not possible to make meaningful inferences about some of the consequences of such commitment, such as academic engagement, or performance. It would also be important to gather further construct-related evidence for the Meaningfulness component of the scale by investigating its association with other constructs that could be expected to support its meaning. In this regard, experimental studies may be helpful to disentangle the effects of satisfaction and meaningfulness and to specifically examine the hypothesis that Level of Commitment will be sustained when Meaningfulness is strong, but with diminished Satisfaction.

[Total word count: 6957 words, including references, tables, figures, but excluding this sentence]

\section{List of references}

Antonovsky, H., \& Sagy, S. (2001). The development of a sense of coherence and its impact on responses to stress situations. The Journal of Social Psychology, 126(2), 213 - 225.

Berzonsky, M.D., \& Kuk, L. (2005). Identity style, psychosocial maturity, and academic performance. Personality and Individual Differences, 39, 235 - 247. 
Boland, J. (2009). Teaching and learning through civic engagement: Prospects for sustainability in teacher education. Issues in Educational Research, 20(1), 1 - 20.

Crawford, A.V., Green, S.B., Levy, R., Lo, W.J., Scott, L., Svetina, D., Thompson, M.S. (2010). Evaluation of parallel analysis methods for determining the number of factors. Educational and Psychological Measurement, 70(6), 885 - 901.

Dalbert, C. (1999). The world is more just for me than generally: About the Personal Belief in a Just World Scale's validity. Social Justice Research, 12, 79 - 98.

Dalbert, C., Lipkus, I.M., Sallay, H., \& Goch, I. (2001). A just and an unjust world: structure and validity of different world beliefs. Personality and Individual Differences, 30, 561 577.

Heine, S.J., Proulx, T., \& Vohs, K.D. (2006). The meaning maintenance model: On the coherence of social motivations. Personality and Social Psychology Review, 10(2), 88 110.

Horstmanshof, L., \& Zimitat, C. (2007). Future time orientation predicts academic engagement among first-year university students. British Journal of Educational Psychology, 77, 703 $-718$.

Iverson, S.V., \& James, J.H. (2010). Becoming “effective" citizens? Change-oriented service in a teacher education program. Innovative Higher Education, 35, 19 - 35.

Krause, K., \& Coates, H. (2008). Students' engagement in first-year university. Assessment \& Evaluation in Higher Education, 33, 493 - 505.

Krypel, M.N., \& Henderson-King, D. (2010). Stress, coping styles and optimism: are they related to meaning of education in students' lives? Social Psychology of Education, 13, $409-424$.

Le, B., \& Agnew, C.R. (2003). Commitment and its theorized determinants: A meta-analysis of the Investment Model. Personal Relationships, 10, 37 - 57. 
Lieberman, M.S. (1998). Commitment, value and moral realism. Cambridge: Cambridge University Press.

Lucas, R.E., \& Donnellan, M.B. (2007). How stable is happiness? Using the STARTS model to estimate the stability of life satisfaction. Journal of Research in Personality, 41, 1091 $-1098$.

Madsen, S.R., \& Turnbull, O. (2006). Academic service learning experiences of compensation and benefit course students. Journal of Management Education, 30, 724 - 742.

Matthews, K.E., Andrews, V., Adams, P. (2010). Social learning spaces and student engagement. Higher Education Research and Development, 30(2), 105 - 120.

Moely, B.E., McFarland, M., Miron, D., Mercer, S., \& Ilustre, V. (2002). Changes in college students' attitudes and intentions for civic involvement as a function of service-learning experiences. Michigan Journal of Community Service Learning, Fall, 18 - 26.

Morosanu, L., Handley, K., O’Donovan, B. (2010). Seeking support: researching first-year students' experiences of coping with academic life. Higher Education Research and Development, 29(6), $665-678$.

O’Connor, B.P. (2000). SPSS and SAS programs for determining the number of components using parallel analysis and Velicer's MAP test. Behavior Research Methods, Instruments, \& Computers, 32(3), $396-402$.

Power, A. (2009). Community engagement as authentic learning with reflection. Issues in Educational Research, 20(1), $57-63$.

Rusbult, C.E., Maritz, J.M., \& Agnew, C.R. (1998). The Investment Model Scale: Measuring commitment level, satisfaction level, quality of alternatives, and investment size. Personal Relationships, 5, 357-391.

Steger, M.F., \& Kashdan, T.B. (2007). Stability and specificity of meaning in life and life satisfaction over one year. Journal of Happiness Studies, 8, 161 - 179. 
Stupans, I., Scutter, S., Pearce, K. (2010). Facilitating student learning: Engagement in novel learning opportunities. Innovative Higher Education, 35, 359 - 366.

Westheimer, J., \& Kahne, J. (2004). What kind of citizen? The politics of educating for democracy. American Educational Research Journal, 41(2), 237 - 269.

Willcoxson, L. (2011). Factors affecting intention to leave in the first, second and third year of university studies: a semester-by-semester investigation. Higher Education Research and Development, 29(6), $623-639$. 